\title{
XXVI. On a repetition of Dr. Kerr's experiments on a new relation between electricity and light
}

\section{J.E.H. Gordon B.A.}

To cite this article: J.E.H. Gordon B.A. (1876) XXVI. On a repetition of Dr. Kerr's experiments on a new relation between electricity and light, Philosophical Magazine Series 5, 2:10, 203-208, DOI: $10.1080 / 14786447608639091$

To link to this article: http://dx.doi.org/10.1080/14786447608639091

曲 Published online: 13 May 2009.

Submit your article to this journal $[\pi$

Џ Article views: 5

Q View related articles $\square$ 


\section{[ 203 ]}

XXVI. On a repetition of Dr. Kerr's Experiments on a new Relation between Electricity and Light. By J. E. H. GorDon, B.A., Gonville and Caius College, Cambridge*.

THAVE been for some months engaged on a repetition of 1 the experiments described by Dr. Kerr in the Philosophical Magazine for November and December 1875. I have as yet been absolutely unable to obtain Dr. Kerr's result; and I think, when I have described the precautions taken, I shall be able to show that either Dr. Kerr's success or my failure is due to some cause not yet noticed by either of us; in any case the cause of the difference in our results will be worth looking for.

\section{The optical arrangements.}

The polarizing apparatus consisted of a Nicol's prism and collimator, as described by me in my last papert. The end of the collimator which carried the prism projected through a hole in a screen, which protected the observer from stray light. The collimating-tube was fixed in cement to the brick experimenting-table.

Monochromatic light was used, generally that of a powerful paraffine lamp, coloured red by means of a test-tube containing coloured liquid and hung in front of the prism.

Sometimes a solar spectrum was thrown on a card, a slit in which admitted one colour to the Nicol.

The analyzing-apparatus.

This, which was all mounted on a massive block of wood cemented to the brick table, consisted :-

1. Of a Babinet's compensator (kindly lent to me by Professor Maxwell).

2. Of a powerful microscope used with a two-inch power, at the back of which a Nicol's prism was fixed. The objective and prism revolved together in a collar. The microscope and collimator were both horizontal. The diagonals of the Nicols were respectively inclined at $\pm 45^{\circ}$ to the horizon ; distance from lens of collimator to compensator $2 \mathrm{ft}$. $6 \mathrm{in}$.

The bands were very distinct. Their apparent distance from centre to centre, as determined by a camera lucida on the eyepiece, upon a sheet of paper 10 inches distant, was $1 \frac{1}{2}$ inch for red light. For their observation the eyepiece of the microscope was furnished with fine cross-wires.

* Communicated by the Author.

$\dagger$ Determination of Verdet's Constunt. Read before the Royal Suciety, June 15, 1876. 


\section{Mr. J. E. H. Gordon on Dr. Kerr's Experiments}

The breadth of the black bands was about $f$ that of the bright ones.

To test the sensitiveness of the apparatus, a black band was brought upon the cross-wires, and a piece of glass ${ }_{8}^{3}$ inch thick and 2 inches square was compressed in the fingers. A very moderate compression served to displace the black band, so that its edge, instead of its centre, came upon the cross-wires, while moderate compression in a small iron screw clamp moved the band, so that instead of the centre of the black band, the centre of the bright band next on the right or left, according as the compression was vertical or horizontal, came on the cross-wire. This corresponds to an apparent displacement of $\frac{3}{4}$ inch, or a retardation of about $\frac{1}{2}$ a wave-length.

\section{The electrical arrangements.}

The coil.-The electricity was produced by a powerful induction-coil by Apps, giving a thick spark 16 inches long in air. It was provided with a vibrator and a clock contactbreaker, both of which were used in the experiments.

The coil was worked by 9 or 10 quart Grove cells. It was managed by an assistant, while fine wires suspended by silk threads carried the secondary current to the optical apparatus.

The coil was placed behind the observer; so that his eyes were not dazzled by the sparks.

\section{The experiments.}

A piece of plate glass 1 inch thick and 6 inches square, had holes drilled, as described by Dr. Kerr, in opposite edges, the bottoms of which holes came within 11 inch of each other.

Quill glass tubes a foot long were put into these holes nearly to the bottom. Inside the quill tubes were stout brass wires, which reached to the bottoms of the holes.

One tube and wire having been put in and the whole apparatus warmed, it was set on one edge on the table, so that the glass tube stood vertical. A kind of cell was made, consisting of two panes of window-glass pressed against the faces of the plate, and projecting above it, and two blocks of cork, the thickness of the plate, between them above the plate. The thin glasses were slightly greased, and the interstices between them and the corks filled up with a little flour-and-water dough. This then formed a cell 2 inches long, $1 \frac{1}{2}$ deep, and 1 inch wide. In the centre was the vertical tube. The cell was now filled with Apps's electrical cement. This is a compound consisting of shellac, \&c., used for perforating glass by means of induction-coils. It is so good an insulator that blocks of glass whose diameter is not more than twice their 
thickness can be perforated when the points of the secondary terminals are imbedded in it. When hot it is nearly as liquid as water. The tube and wire were taken up and replaced once or twice, so that the liquid cement might fill every interstice. When the cement was hard, the side glasses and corks were removed; and, the plate being reversed, the second conductor was fixed in the same way.

Next day the experiment was tried. The plate was mounted with its faces perpendicular to the line of light, its conductors horizontal, and its position such that the light passed between their points. The coil was then worked. The insulation was so good that, while wires from each pole were connected to the wires let into the glass, sparks of 12 inches long were easily obtained between the terminals. The coil was worked both with the vibrator and with the clock, with currents continued both for short and long periods, currents in both directions both quickly and slowly alternated, and both with and without Leyden jars.

In not one of the experiments was any effect whatever observed on the light. The compensator was then removed, and, the field being darkened, all the above experiments were repeated. No return of the light or any other effect whatever was obtained.

But Dr. Kerr has stated that the electrified glass acts like a crystal. Now we know that the action of crystal on polarized light increases with the thickness through which the light is transmitted. I thought therefore that if, instead of sending the light through 1 inch of electrified glass, I could send it through 15 or 20 inches the effect produced would be so much increased that, if my having been unable to see it in the former case arose from its smallness and not from its absence, I should now be able to see it. I therefore had a piece of fine plate glass prepared, 20 inches by 10 and $\frac{3}{4}$ of an inch thick, and its ends polished. Light passing in at one end and out at the other had then to pass through 20 inches of glass. I then pasted strips of tinfoil 15 inches long on each side, and placed the glass vertical in the line of light.

I then connected the opposite tinfoils to the secondary poles and worked the coil. No effect was obtained. But only sparks four or five inches long could be used, owing to the electricity springing round the glass.

It was then resolved to insulate the latter so as to allow a greater stress to be applied to it.

For this purpose a box was made of inch mahogany, whose inside dimensions were, length 24 inches, depth 16 , breadth 7 . Two pieces of barometer-tube being fixed horizontally across 
it, 3 inches from the bottom, the glass was set on one of its long edges on them, in the centre of the box. Two holes $1 \frac{1}{4}$ inch in diameter were made opposite to each other in the ends. Into these plugs of mahogany, whose inside ends were padded with leather, were inserted, so that the leather ends pressed on the centres of the end edges of the glass. Holes being made in the outside ends of these plugs, long brass stair-rods were put through them, so that the middles of the rods were in the plugs and the ends projected horizontally in both directions. The ends being tightly drawn together with string, the elasticity of the rods pressed the plugs tightly upon the glass. The plugs and leather were slightly oiled.

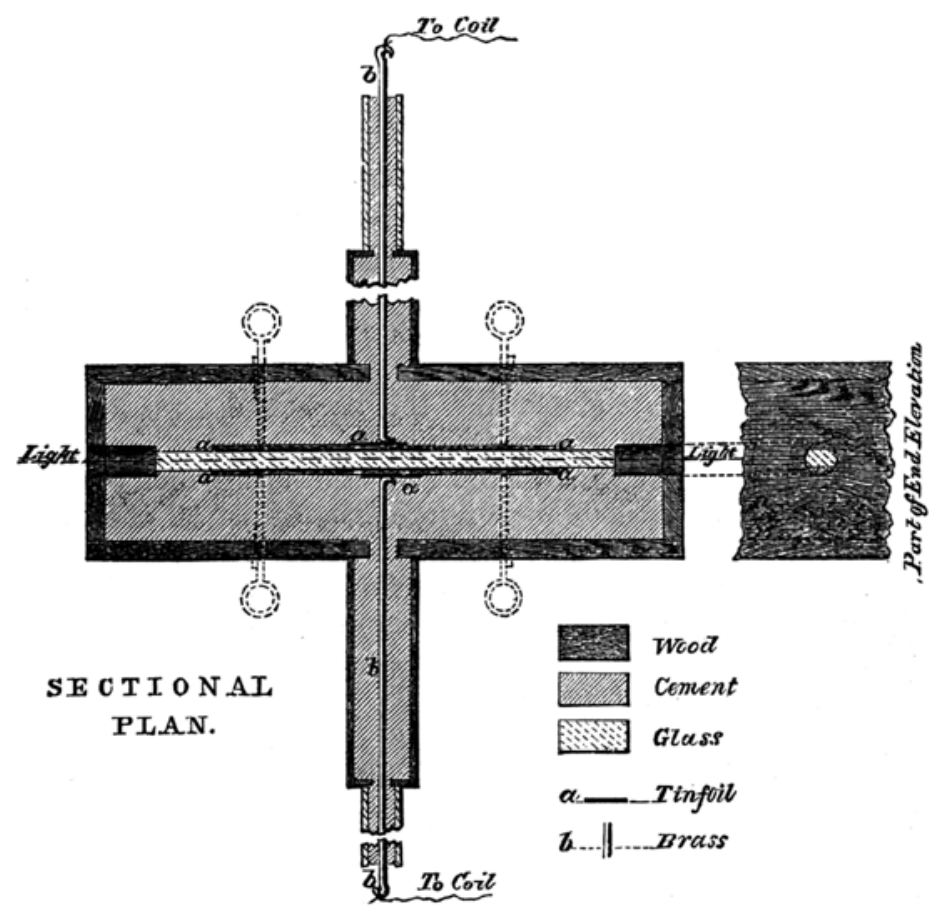

Two pieces of tinfoil 15 inches by 5 , were pasted on thin slips of soft wood, and placed symmetrically on the sides of the glass. Each was kept in position by two stout pointed wires (kitchen skewers), which were passed through holes in the mahogany, and whose points stuck into the soft wood carrying the tinfoil, and pressed it against the glass. Each skewer was fixed by a nail driven alongside it into the mahogany. At the centre of each side, and at right angles to it, was fixed 
a wooden box 3 inches square and 10 inches long; a lampchimney fixed at the end continued the length another 6 inches.

A stout brass wire, protected by a glass tube where it passed through the mahogany, was fixed along the axis of each projecting box and lamp-glass, and pressed against a little bit of tinfoil pasted on the outside of the strip of wood which held the tinfoil against the glass. A short bit of wire let into the wood connected the small bit of tinfoil with the large one. The whole of the box, side boxes, and lamp-glasses were now filled with the cement already described. About $115 \mathrm{lbs}$. were used ; it was all melted at once, and poured in. As it was not convenient to warm the mahogany case, the cement was heated considerably above its melting-point, so that it might warm all the wood and glass before commencing to set.

While it was setting (which took about 4 days) the stairrods were every few hours removed from the end plugs, and the latter twisted round a few times, and occasionally removed for a few seconds to be re-oiled.

When the cement was quite set, the plugs were removed, leaving at each end a cylindrical cavity 2 inches deep, at the bottom of which an inch of the edge of the glass could be seen. When these portions of the glass had been cleaned with a little benzine, it was found that an object placed outside one plug-hole could be well seen from the other through the 20 inches of glass.

The skewers which had not been previously touched were now drawn out with some difficulty. The box being laid on its side, one of them previously heated in a spirit-lamp was replaced for a moment, so as to melt the cement at the edges of each hole; a little fresh cement was now poured in. When it solidified, the holes were completely filled up; on trying the box with the coil the insulation was all that could be desired. While the poles were connected to the secondary terminals, sparks of 11 and 12 inches were easily obtained between the latter. When the terminals were separated too far for the sparks to pass, the peculiar sound which accompanies the sudden charging of a condenser unable to discharge was heard in the box, showing that neither of the tinfoils had shifted.

The box was now placed between the Nicols, so that the light passed from one plug-hole to another. Every experiment which had been performed with the perforated glass was repeated with the box. Not the slightest effect of any sort or kind was observed on the light.

It is very likely that $I$ have omitted some precautions taken by Dr. Kerr ; but I do not think that I have omitted any described in his paper. 
If Dr. Kerr can show me what mistake I have made, no one will be better pleased than myself, as the establishment of such a relation as, according to Dr. Kerr, exists between electricity and light will be a most important step in physical science.

Pixholme, Dorking,

August 5, 1876.

XXVII. Note in regard to a Multiple Differentiation of a certain expression. By J.W. L. GLAISHER, M.A., F.R.S.*

CONSIDER the multiple definite integral

$$
\begin{aligned}
\int_{0}^{\infty} \int_{0}^{\infty} \int_{0}^{\infty} \ldots \exp \left(-a_{1} x_{1}^{2}-a_{2} x_{2}^{2} \ldots-a_{n} x_{n}^{2}\right. \\
\left.-\frac{q}{x_{1}^{2} x_{2}^{4} x_{3}^{8} \ldots x_{n}^{2^{n}}}\right) d x_{1} d x_{2} \ldots d x_{n}, .
\end{aligned}
$$

where, as is convenient in printing complicated exponentials, $\exp (a)$ is written for $e^{a}$.

By the aid of the well-known integral

$$
\int_{0}^{\infty} \exp \left(-a x^{2}-\frac{b}{x^{2}}\right) d x=\frac{\sqrt{ } \pi}{2 \sqrt{ } a} \exp \{-2 \sqrt{ }(a b)\},
$$

we readily see that the integral (1)

$$
\begin{array}{r}
=\left(\frac{\sqrt{ } \pi}{2}\right)^{n} \frac{1}{\sqrt{ }\left(a_{1} a_{2} \ldots a_{n}\right)} \exp \left(-2^{2\left(1-\frac{1}{2^{n}}\right)} \sqrt{ } a_{n} \cdot \sqrt[4]{ } a_{n-1} \cdot \sqrt[8]{ } a_{n-2} \ldots\right. \\
\left.\sqrt[2^{n}]{a_{1}} \cdot \sqrt[2^{n}]{q}\right) . . \quad \text { (2) }
\end{array}
$$

Now from an inspection of the integral (1) it is evident that if we denote by $u$ the quantity (2), then, $i$ being any integer,

$$
\left(\frac{d}{d a_{1}}\right)^{i}\left(\frac{d}{d a_{2}}\right)^{2 i}\left(\frac{d}{d a_{3}}\right)^{4 i} \ldots\left(\frac{d}{d a_{n}}\right)^{2^{n} i} u=\left(\int_{-\infty}^{q} d q\right)^{i} u ; .
$$

viz. the differential expression on the left-hand side of $(3)$ is equal to the $n$th integral of $u$ with regard to $q$. It is clear that the quantity subject to the exponential sign in (2) need not be negative; so that, if we take

$$
-2^{2\left(1-\frac{1}{2^{n}}\right)} \sqrt[2^{n}]{q}=\sqrt[2^{n}]{p}
$$

and put $i=1$ (whereby there is no loss of generality), the theorem is that if

$$
\begin{gathered}
v=\frac{1}{\sqrt{ }\left(a_{1} a_{2} \ldots a_{n}\right)} \exp \left(\sqrt{ } a_{n} \cdot \sqrt{ } a_{n-1} \cdot \sqrt[B]{ } a_{n-2} \ldots \cdot z^{n} a_{1} \cdot \cdot^{n} p\right) \\
* \text { Communicated by the Author. }
\end{gathered}
$$

